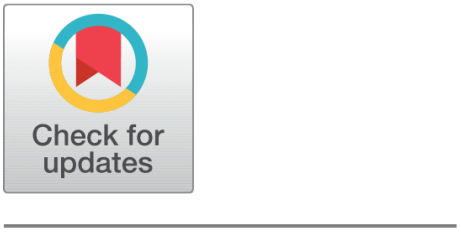

OPEN ACCESS

Received: 09-06-2020

Accepted: 08-07-2020

Published: 27-07-2020

Editor: Dr. Natarajan Gajendran

Citation: Stephen Leon J, Bharathiraja G, Jayakumar V (2020)

Experimental and numerical investigations of optimum process window for friction stir welding using flat faced tool pin. Indian Journal of Science and Technology 13(26): 2609-2624. https://doi.org/ 10.17485/IJST/v13i26.867

*Corresponding author. J Stephen Leon

Department of Mechanical Engineering, Saveetha School of Engineering, Saveetha Institute of Medical and Technical Sciences, Chennai, Tamilnadu stephenleonj@gmail.com

Funding: None

Competing Interests: None

Copyright: @ 2020 Stephen Leon, Bharathiraja, Jayakumar. This is an open access article distributed under the terms of the Creative Commons Attribution License, which permits unrestricted use, distribution, and reproduction in any medium, provided the original author and source are credited.

Published By Indian Society for Education and Environment (iSee)

\section{Experimental and numerical investigations of optimum process window for friction stir welding using flat faced tool pin}

\author{
J Stephen Leon ${ }^{1}$ *, G Bharathiraja ${ }^{1}$, V Jayakumar ${ }^{2}$ \\ 1 Department of Mechanical Engineering, Saveetha School of Engineering, Saveetha Institute \\ of Medical and Technical Sciences, Chennai, Tamilnadu \\ 2 Department of Mechanical Engineering, Amrita School of Engineering, Chennai, Amrita \\ Vishwa Vidyapeetham, Tamilnadu
}

\section{Abstract}

Background/Objectives: In friction stir welding, tools with flat faced pin delivers better weld quality than cylindrical pin. In flat faced pin, improper selection of process parameters often results premature tool failure. Being easily controllable process parameters, proper selection of tool rotation speed with respect to the tool advancing speed not only avoids unwanted weld defects but also enhances tool life. Methods: An integrated experimental and numerical comparative study is made between air and water cooled processes to understand the effects of heat dissipation through the boundaries on temperature distribution. Findings: Optimum range of Pseudo Heat Index $(\mathrm{PHI})$ is achieved by comparing the obtained temperature distribution with material softening temperature. Optimum range of weld speed with respect to the tool rotation speed is derived through the optimum Pseudo heat index. Experimental study on the joint strength validates the proposed optimal process parameter ranges.

Novelty : This study outlines a novel approach to develop an optimum process window based on PHI for air and water cooled friction stir welding using tools with flat faced pin.

Keywords: Optimization; friction stir welding; thermomechanical; pseudo heat index; experimentation; numerical modeling

\section{Introduction}

Friction stir welding (FSW) is a metal joining process primarily developed to join readily oxidising materials in molten stage. This is achieved by carrying out the entire metal joining process below solidus temperature of the material to be joined. In friction stir welding work piece is clamped together and the rotating tool is allowed to slide along the weld line. The frictional heat produced by the relative motion between the workpiece and tool contact surface is the major heat source for this metal joining process. The entire process is divided as plunging, dwell and welding stage based on the position of tool. Tool consists of two major parts namely shoulder and tool pin. Rotating tool is allowed to penetrate through the workpiece till the shoulder gets into contact with the 
Stephen Leon et al. / Indian Journal of Science and Technology

workpiece as shown in Figure 1. Up to this stage it is called as plunging in which the 
entire tool pin inserted into the parental metal. Generated heat along the tool/matrix contact surfaces plasticises the material under the tool shoulder. Torque produced by the rotating tool, stirs the plasticised material to flow around the pin which develops a thermo-mechanically affected stir zone under the tool shoulder in the dwell stage. Tool retains its position in this stage till the stir zone reaches quasi steady state temperature. Once the maximum process temperature is achieved, the rotating tool is allowed to slide along the weld line in the welding stage. Proper selection of tool sliding velocity retains the maximum process temperature throughout the process.

In friction stir welding although major part on total heat is generated in the shoulder/matrix interface, considerable quantity of heat is also generated along the pin/matrix contact surface. Apart from heat generation, tool pin has a major contribution in material flow in the stir zone. Comparing with cylindrical shaped pin side, flat faced pin sides enhances the material flow which results improvement in the weld quality ${ }^{(1)}$. Illangovan et al. ${ }^{(2)}$ analysed post weld microstructure and weld properties of friction stir welding using different polygonal shaped tool pin and concluded that square pin exhibits comparatively good quality weld joint. Numerical analysis has been done to understand the effects of usage of noncircular tool pin and corresponding changes in temperature history was studied by Stephen leon et al. ${ }^{(3)}$. Sabeerushen et al. ${ }^{(4)}$ joined dissimilar metals using triangular and hexagonal tool pins and the results reveals that the hexagonal tool pin delivers better joint comparing with other polygonal shapes. A comparative analysis done by Nabeel et al. ${ }^{(5)}$ clarifies the changes in microstructure and mechanical properties corresponding to the change in tool pin geometry.

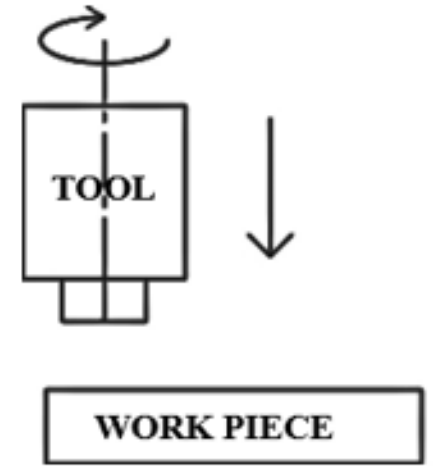

(a)



(b)

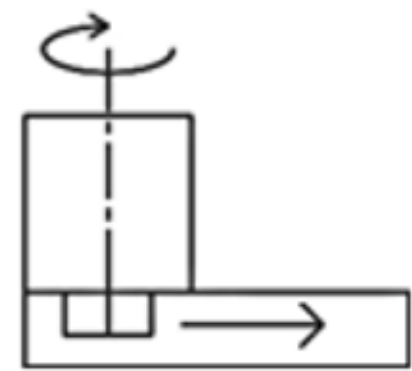

(c)

Fig 1. Stages of friction stir welding process: (a) plunging, (b) dwelling and (c) welding

The shape of the pin not only influences the metal flow but also alters the amount of heat generation which in turn changes the peak temperature ${ }^{(6)}$. Various analysis on the effects of tool pin geometries proved that variation in the post weld properties of the friction stir joint depends on the heat generation and subsequent temperature rise at various points in and around the stir zone. Microstructure analysis done by Liang et al. ${ }^{(7)}$ observed increase in the grain size and diminishing strengthening properties in heat affected zone (HAZ) on the parental metal while it is subjected to thermal cycles during the welding process. Apart from these various researches ${ }^{(8-10)}$ proved that due to the cyclic variation in the heat supply in heat affected zones, the strengthening precipitates were sacrificed by the coarsening of grains which makes the HAZ as low strength region.

The temperature distribution along the parental metal during welding not only depends on the amount of heat generation but also depends on the heat dissipating boundary conditions of the parental metal. Simulation results obtained by Fratini et al. ${ }^{(11)}$ noticed reduction in thermal flow while the boundaries are cooled by water. Experimental study by Lie et al. ${ }^{(12)}$ observed reduction in the grain size and improvement in mechanical properties along the heat affected zone in under-water friction stir welding. Thermal conductivities of other contacts like backing plate and clamp also play a vital role in heat conduction ${ }^{(13)}$. Temperature distribution along the parental metal is estimated using numerical analysis by Soundararajan et al. ${ }^{(14)}$ considering the thermal contact conditions of the heat dissipating boundary lies between the backing plate and the parental metal.

Although several researches had been done on this, there are limited researches are carried out on friction stir welding with flat faced pin. Tool pin with flat faces in friction stir welding tool delivers comparatively better weld quality than the circular $\mathrm{pin}^{(15)}$. Premature tool failure is the major problem on the usage of non-circular pin. Especially in underwater welding, as the joining process is carried out in low process temperature, the traverse force experienced by the tool pin is too high which requires an optimisation of process parameters with respect to the selected tool pin geometry. Adition of assisting heat source ${ }^{(16)}$ in underwater welding is also a very difficult task. Tool failure during the process depends on the maximum stress generated in 
the pin as it is completely immersed into the workpiece and experiences more opposing force than other parts of the tool. The maximum principal stress developed in the tool pin depends on the temperature gradient at different points in the stir zone as the strength of the opposing material is a direct function of its temperature. Arora et al. ${ }^{(17)}$ concluded that the maximum shear stress in the tool pin is almost equal to the shear strength of the parental metal to be joined with respect to the process temperature. It reveals that the increase in temperature reduces shear stress on the tool and increases tool life.

Selection of higher process temperature may reduce the principal stress in the tool pin but it increases the temperature in heat affected zone which eradicates the post weld properties of the weld joint ${ }^{(18)}$. So peak process temperature has to be optimised to a minimal effect on heat affected zone. The temperature distribution along the workpiece during the process depends on the balance between heating and cooling rate. Proper selection of process parameters according to the cooling boundary conditions ensures proper distribution of temperature gradient not only in the stir zone but also in the heat affected zone. In this paper, temperature rise during the process is observed in stir as well as heat affected zone for different process parameter levels. Process parameters are optimised to achieve peak process temperature closer to the material softening temperature so that the opposing force given by the material for the tool movement can be drastically reduced. Maximum possible rise in process temperature is estimated through the experimental analysis on joint strength with respect to the temperature rise.

\section{Materials and Methods}

\subsection{Experimental study}

Process parameters can be optimized through the estimation of maximum temperature and transferred heat at various points in stir and heat affected zone during the process for the given input condition. Total heat generation for the chosen process parameters can be obtained analytically through readily available analytical equations on the usage of tools with circular pin. The complex geometry of the tools with non-circular pin makes the analytical estimation difficult. Especially the analytical estimation of heat generated by the pin-side/matrix contact surface is too complicated as the distance from the axis of rotation to the contact boundary of the non-circular pin side is not uniform. The rate of heat generation during FSW is equal to the mechanical power associated with moving tool ${ }^{(19)}$. It indicates that the total heat generation can be estimated through experimentally obtained power consumed by the tool during the process. In the present study, torque based estimation of heat generation method is adopted.

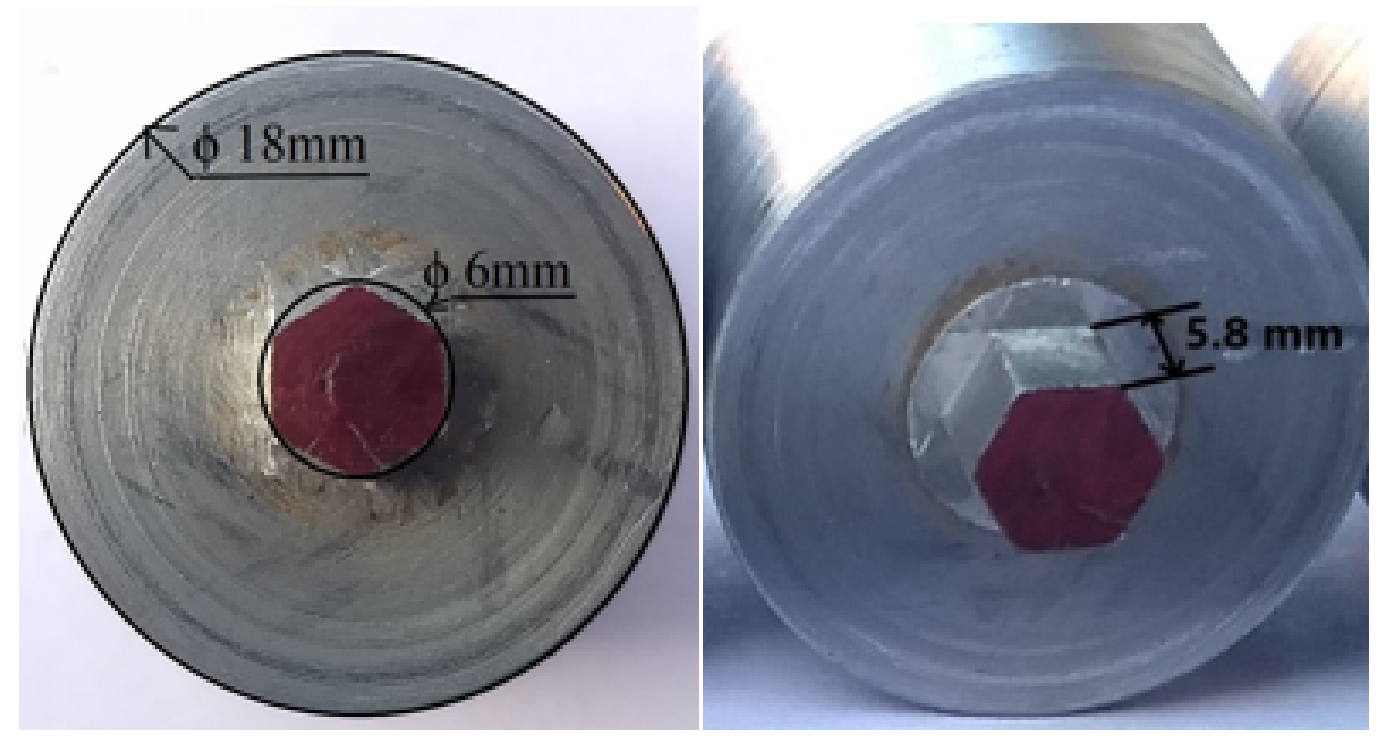

Fig 2. Tool with hexagonal pin 




Fig 3. Experiment layout (dimensions are in $\mathrm{mm}$ )

Experiments were conducted using HURCO VMX24 machine centre AA2024-T3 plates (150mm X 50mm X 6mm) using tool with hexagonal shaped pin as shown in Figure 2. K-type thermocouples (TC) were placed in different locations to ensure temperature recordings cover all the zones (heat affects zone and non-affected zone) as shown in Figure 3 to identify the variation in thermal history along the heat affected zone. To consider the temperature difference between retreating and advancing side, average temperature is calculated between the temperatures measured in retreating and advancing side at the same location [ Table 1]. Torque generated during the process is observed using dynamometer Type 9129A. In order to understand the effects of increasing heat input intensity during welding, trials are done by varying too rotational speed from $800 \mathrm{rpm}$ to $1100 \mathrm{rpm}$ on both air and water cooled process and recorded thermal histories are listed in Table 1 . Weld quality and joint strength is analysed for each trail using macrostructure analysis, hardness test and tensile test.

Table 1. Experiment details

\begin{tabular}{llllll}
\hline Mode of cooling & Tool rotation speed $(\mathrm{rpm})$ & Torque observed $(\mathrm{Nm})$ & \multicolumn{3}{c}{ Measured temperature Avg. (in $\left.{ }^{\circ} \mathrm{C}\right)$} \\
& & & TC1 & TC2 & TC3 \\
\hline \multirow{3}{*}{ Air cooled } & 800 & 25.12 & 385.16 & 330.32 & 249.23 \\
& 900 & 24.46 & 390.78 & 334.54 & 250.12 \\
& 1000 & 23.52 & 393.45 & 336.56 & 254.67 \\
& 1100 & 21.97 & 395.67 & 337.12 & 257.78 \\
\hline \multirow{3}{*}{ Water cooled } & 800 & 26.12 & 332.45 & 247.23 & 128.97 \\
& 900 & 25.02 & 334.67 & 249.32 & 129.42 \\
& 1000 & 23.87 & 335.12 & 254.12 & 134.56 \\
& 1100 & 22.12 & 336.34 & 256.02 & 138.64 \\
\hline
\end{tabular}

\subsection{Formulation of numerical equations}

In order to analyse the variation in temperature gradient along the stir as well as heat affected zone with respect to the distance measured from the weld line, maximum temperature should be estimated during welding. Peak process temperature depends on total heat generation in the tool/matrix interface, welding speed and the thermal properties of tool as well as workpiece materials.

Total heat generated based on the experimentally recorded torque are calculated by ${ }^{(19)}$,

$$
Q_{\text {Total }}=\text { Torque observed } x \text { tool angular velocity }
$$

Peak temperature for the given welding speed (v) can be estimated using the calculated input heat by ${ }^{(20)}$

$$
\frac{T_{\max }}{T_{s}}=1.56 \times 10^{-4} \times Q_{e f f}+0.54
$$




$$
\text { Here, } \mathrm{Q}_{\text {eff }}=\frac{Q_{\text {Total }}}{\text { weld velocity }}
$$

$\mathrm{T}_{s}$ is melting temperature of the parental metal.

Table 2. Analytical estimations

\begin{tabular}{|c|c|c|c|c|c|}
\hline Mode of cooling & Tool speed (rpm) & Torque $(\mathrm{Nm})$ & Total power (QTotal) $(\mathrm{J} / \mathrm{mm})$ & Eff. heat (Qeff) $(\mathrm{J} / \mathrm{mm})$ & $\mathrm{T}_{\max }\left(\right.$ in $\left.^{\circ} \mathrm{C}\right)$ \\
\hline \multirow{4}{*}{ Air cooled } & 800 & 25.12 & 2103.38 & 1259.51 & 443.36 \\
\hline & 900 & 24.46 & 2304.13 & 1379.72 & 454.65 \\
\hline & 1000 & 23.52 & 2461.76 & 1474.11 & 463.52 \\
\hline & 1100 & 21.97 & 2529.48 & 1514.66 & 467.32 \\
\hline \multirow{4}{*}{ Water cooled } & 800 & 26.12 & 2187.11 & 1309.65 & 448.07 \\
\hline & 900 & 25.02 & 2356.88 & 1411.31 & 457.62 \\
\hline & 1000 & 23.87 & 2498.39 & 1496.04 & 465.58 \\
\hline & 1100 & 22.12 & 2546.75 & 1525.00 & 468.30 \\
\hline
\end{tabular}

All the input parameters, mechanical and thermal properties of parental metal and backing plate are given in Tables 3, 4 and 5 .

Table 3. Mechanical and thermal properties of work piece(AA2024-T3)

\begin{tabular}{ll}
\hline Property/parameter & Value \\
\hline Thermal conductivity $(\mathrm{W} / \mathrm{mK})$ & 151 \\
Specific Heat capacity $\left(\mathrm{J} / \mathrm{g}^{\circ} \mathrm{C}\right)$ & 0.875 \\
Density $(\mathrm{g} / \mathrm{cc})$ & 2.78 \\
\hline
\end{tabular}

Table 4. Mechanical and thermal properties of backing plate (Mild steel 350 grade)

\begin{tabular}{ll}
\hline Property/parameter & Value \\
\hline Thermal conductivity $(\mathrm{W} / \mathrm{mK})$ & 51.5 \\
Specific Heat capacity $(\mathrm{J} / \mathrm{Kg} \mathrm{K})$ & 425 \\
Density $(\mathrm{Kg} / \mathrm{m} 3)$ & 7800 \\
\hline
\end{tabular}

Table 5. Input properties/parameters

\begin{tabular}{ll}
\hline Property/parameter & Value \\
\hline Shoulder diameter $(\mathrm{mm})$ & 18 \\
Circumscribed pin diameter $(\mathrm{mm})$ & 6 \\
Height of the pin $(\mathrm{mm})$ & 5.8 \\
Workpiece thickness $(\mathrm{mm})$ & 6 \\
Applied force $(\mathrm{kN})$ & 10 \\
Tool rotation speed $(\mathrm{rpm})$ & 800 to 1100 \\
Initial temperature of workpiece $\left({ }^{\circ} \mathrm{C}\right)$ & 27 \\
Weld velocity $(\mathrm{mm} / \mathrm{min})$ & 100 \\
\hline
\end{tabular}

In order to predict the temperature distribution along the parental metal finite element model is developed based on the analytically calculated input temperature. 


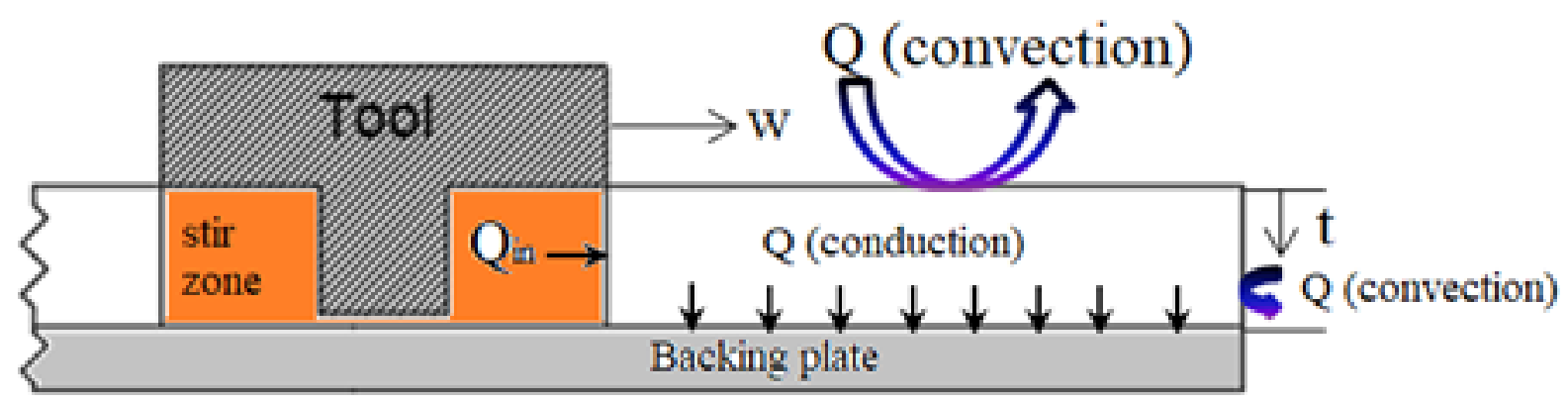

Fig 4. Heat transfer modes during friction stir welding

Following assumptions are made in this analysis:

- Temperature along the tool/matrix contact surface is constant and it is equal to the estimated maximum temperature in Table 2.

- Thermal Contact resistance is negligible between the bottom surface of the workpiece and the backing plate.

- The upper surface of the workpiece is assumed to be subjected to uniform convective environment as shown in Figure 4. In reality although some parts of the upper surface is covered with clamp, the area covered by the clamp is comparatively very less and can be neglected.

In the current analysis mild steel is used as backing plate material as the previous investigations ${ }^{(21)}$ divulge that usage of mild steel results improved ultimate tensile strength on the welding of AA204-T6 material.

According to the subjected boundary conditions, the workpiece is divided into rectangular elements. For air as well as water cooled friction stir welding process, inside nodes of the workpiece are not directly affected by the convective cooling environment and they are purely subjected to the conductive heat transfer. All other nodes existing in the surfaces are subjected to convective as well as conductive mixed heat transfer conditions.

If $w$ is the width of the workpiece, $t$ is the thickness of the workpiece, $T_{\infty}$ is the temperature of the surrounding medium, $\mathrm{K}_{1}$ is the thermal conductivity of the workpiece, $\mathrm{K}_{2}$ is the thermal conductivity of the backing plate and $\mathrm{h}$ is the heat transfer coefficient of the surrounding medium, then,

The temperature of the inside nodes $\left(\mathrm{T}_{\alpha, \beta}\right)$ depend on the temperature of the surrounding nodes and can be obtained by,

$$
\frac{\Delta t}{2}\left(\frac{T_{\alpha-1, \beta}-T_{\alpha, \beta}}{\Delta w}\right]+\Delta w\left(\frac{T_{\alpha, \beta+1}-T_{\alpha, \beta}}{\Delta t}\right]+\frac{\Delta t}{2}\left(\frac{T_{\alpha+1, \beta}-T_{\alpha, \beta}}{\Delta w}\right]=0
$$

Top surface except corner node,

$$
h \Delta w(T \infty-T \alpha, \beta)+K_{1} \frac{\Delta t}{2}\left(\frac{T_{\alpha-1, \beta}-T_{\alpha, \beta}}{\Delta w}\right]+K_{1} \Delta w\left(\frac{T_{\alpha, \beta-1}-T_{\alpha, \beta}}{\Delta t}\right]+K_{1} \frac{\Delta t}{2}\left(\frac{T_{\alpha+1, \beta}-T_{\alpha, \beta}}{\Delta w}\right]=0
$$

Bottom surface except corner node

$$
\begin{aligned}
& {\left[K_{1} \frac{\Delta t}{2}+K_{2} \frac{\Delta t}{2}\right]\left[\frac{T_{\alpha-1, \beta}-T_{\alpha, \beta}}{\Delta w}\right]+K_{2} \Delta w\left[\frac{T_{\alpha, \beta-1}-T_{\alpha, \beta}}{\Delta t}\right]+\left[K_{1} \frac{\Delta t}{2}+K_{2} \frac{\Delta t}{2}\right]\left[\frac{T_{\alpha+1, \beta}-T_{\alpha, \beta}}{\Delta w}\right]+} \\
& K_{1} \Delta w\left[\frac{T_{\alpha, \beta+1}-T_{\alpha, \beta}}{\Delta t}\right] \Delta t=0
\end{aligned}
$$

Side surface except two corners,

$$
h \triangle w(T \infty-T \alpha, \beta)+K_{1} \frac{\Delta w}{2}\left[\frac{T_{\alpha, \beta+1}-T_{\alpha, \beta}}{\Delta t}\right]+K_{1} \triangle t\left[\frac{T_{\alpha-1, \beta}-T_{\alpha, \beta}}{\Delta w}\right]+K_{1} \frac{\Delta w}{2}\left[\frac{T_{\alpha, \beta-1}-T_{\alpha, \beta}}{\Delta t}\right]=0
$$

Top corner,

$$
h\left[\frac{\Delta w}{2}+\frac{\Delta t}{2}\right]\left(T_{\infty}-T_{\alpha, \beta}\right)+K_{1} \frac{\Delta t}{2}\left[\frac{T_{\alpha-1 . \beta}-T_{\alpha, \beta}}{\Delta w}\right]+K_{1} \frac{\Delta w}{2}\left[\frac{T_{\alpha, \beta-1}-T_{\alpha, \beta}}{\Delta t}\right]=0
$$


Bottom corner,

$$
h\left[\frac{\Delta w}{2}+\frac{\Delta t}{2}\right]\left(T_{\infty}-T_{\alpha, \beta}\right)+K_{1} \frac{\Delta w}{2}\left[\frac{T_{\alpha, \beta+1}-T_{\alpha, \beta}}{\Delta t}\right]+K_{1} \frac{\Delta t}{2}\left[\frac{T_{\alpha-1, \beta}-T_{\alpha, \beta}}{\Delta w}\right]=0
$$

Under normal welding conditions, when the top and side surfaces of the workpiece is subjected to the convective heat transfer with atmospheric air, following boundary and initial conditions are adopted :

- B.C1: $\mathrm{Q}=\mathrm{h}_{\text {air }} \mathrm{A}_{t}\left(\mathrm{~T}-\mathrm{T}_{\infty}\right)$ when $\tau>0$ at $0 \leq \mathrm{X} \leq \mathrm{L} \& \mathrm{Y}=\mathrm{t}$

- B.C2: $\mathrm{Q}=\mathrm{h}_{\text {air }} \mathrm{A}_{s}\left(\mathrm{~T}-\mathrm{T}_{\infty}\right)$ when $\tau>0$ at $0 \leq \mathrm{Y} \leq \mathrm{H} \& \mathrm{X}=\mathrm{w}$

- B.C3: $\mathrm{Q}=\mathrm{K}_{2} \mathrm{~A}_{b} \frac{\Delta T}{\Delta Y}$ when $\tau>0$ at $0 \leq \mathrm{X} \leq \mathrm{w} \& \mathrm{Y}=0$

During under water welding, the top and side surfaces of the workpiece is subjected to the convective heat transfer with surrounding water, following boundary and initial conditions are adopted :

- B.C1: $\mathrm{Q}=\mathrm{h}_{\text {water }} \mathrm{A}_{t}(\mathrm{~T}-\mathrm{T} \infty)$ when $\tau>0$ at $0 \leq \mathrm{X} \leq \mathrm{w} \& \mathrm{Y}=\mathrm{t}$

- B.C2: $\mathrm{Q}=\mathrm{h}_{\text {water }} \mathrm{A}_{s}\left(\mathrm{~T}-\mathrm{T}_{\infty}\right)$ when $\tau>0$ at $0 \leq \mathrm{Y} \leq \mathrm{t} \& \mathrm{X}=\mathrm{w}$

- B.C3: $\mathrm{Q}=\mathrm{K}_{2} \mathrm{~A}_{b} \frac{\Delta T}{\Delta Y}$ when $\tau>0$ at $0 \leq \mathrm{X} \leq \mathrm{L} \& \mathrm{Y}=0$

Initial condition:

- $\mathrm{T}=27^{\circ} \mathrm{C}$ at $0 \leq \mathrm{X} \leq \mathrm{w} \& 0 \leq \mathrm{Y} \leq \mathrm{t}$

Here, $\mathrm{A}_{t}=\mathrm{A}_{b}$ is top and bottom surface area, $\mathrm{A}_{s}$ is side surface area, $\mathrm{h}_{\text {air }}$ is convective heat transfer coefficient between workpiece and atmospheric air, $\mathrm{h}_{\text {water }}$ is convective heat transfer coefficient between workpiece and water, $\mathrm{K}_{2}$ is the thermal conductivity of the backing plate, $\mathrm{t}$ is thickness of the workpiece, $\mathrm{w}$ is the width of the workpiece and $\tau$ refers to time.

\section{Results and Discussion}

\subsection{Thermal history}

3.1.1 Stir zone

Thermal field analysis during the process helps to predict strain rate of the material under the shoulder, shear strength of the material and its opposing force for the tool movement. Experimental investigation of thermal history in this zone is difficult as it undergoes severe plastic deformation during the process. So, temperature rise at various points are obtained by solving equations [Eqns. 5-9] simultaneously using iterative method. The results are shown in Figure 5. Maximum temperature achieved during the process depends on the effective heat supply through the heat input boundaries. Effective heat supply is directly proportional to the tool rotation speed when the feed rate is constant [ Table 2].

Increase in tool rotational speed flattens the temperature gradient curve [ Figure 5]. Flat curve indicates uniform temperature distribution in all the point of stir zone. Increase in temperature reduces the shear strength of the material. From this it can be understood that flat curves of temperature distribution is an indication of uniform reduction in material shear strength which enhances the material flow around the tool pin. This reveals that the attained flat curves through higher heat input helps the tool to transfer maximum of its rotational velocity to the material that it handles under its shoulder. So, it can be concluded that flat temperature gradient curves indicates higher slip rate and increase in slip rate leads to the defect free welds in stir zone ${ }^{(21)}$.

For higher tool rotational speed torque experienced by the tool reduces [ Table 2]. Increase in slip rate reduces force on the tool which reduces torque. When the process peak temperature reaches closer to the solidus temperature of the parental metal, material layer in the tool/matrix contact surface tends to become liquid which reduces the frictional heat generation. So, peak temperature cannot be increased beyond solidus temperature. For the current analysis, it can be understood, the increase in tool rotation from $1000 \mathrm{rpm}$ to $1100 \mathrm{rpm}$, does not impact more in process peak temperature both in air and water cooled joining process. It can be noticed [ Table 2] that at $1100 \mathrm{rpm}$ torque developed is almost same for air as well as water cooled friction stir welding process. This also indicates that slip rate increased to a maximum value and further increase in tool rotational speed will not have a considerable effect on torque irrespective of its boundary conditions and peak process temperature cannot be increased further.

Comparative analysis between air and water cooled friction stir welding [ Figure 5] reveals that temperature gradient is quite high in water cooled process due to the excess cooling rate. This indicates non-uniform temperature distribution in stir zone in water cooled process which increases opposing force to the tool movement. Increase in force exerted by the material on the tool leads to premature tool failure. Flat curves are attained only when the heat input is high. So water cooled welding should be carried out on maximum possible process temperature which has to be optimised through the maximum possible heat input. 

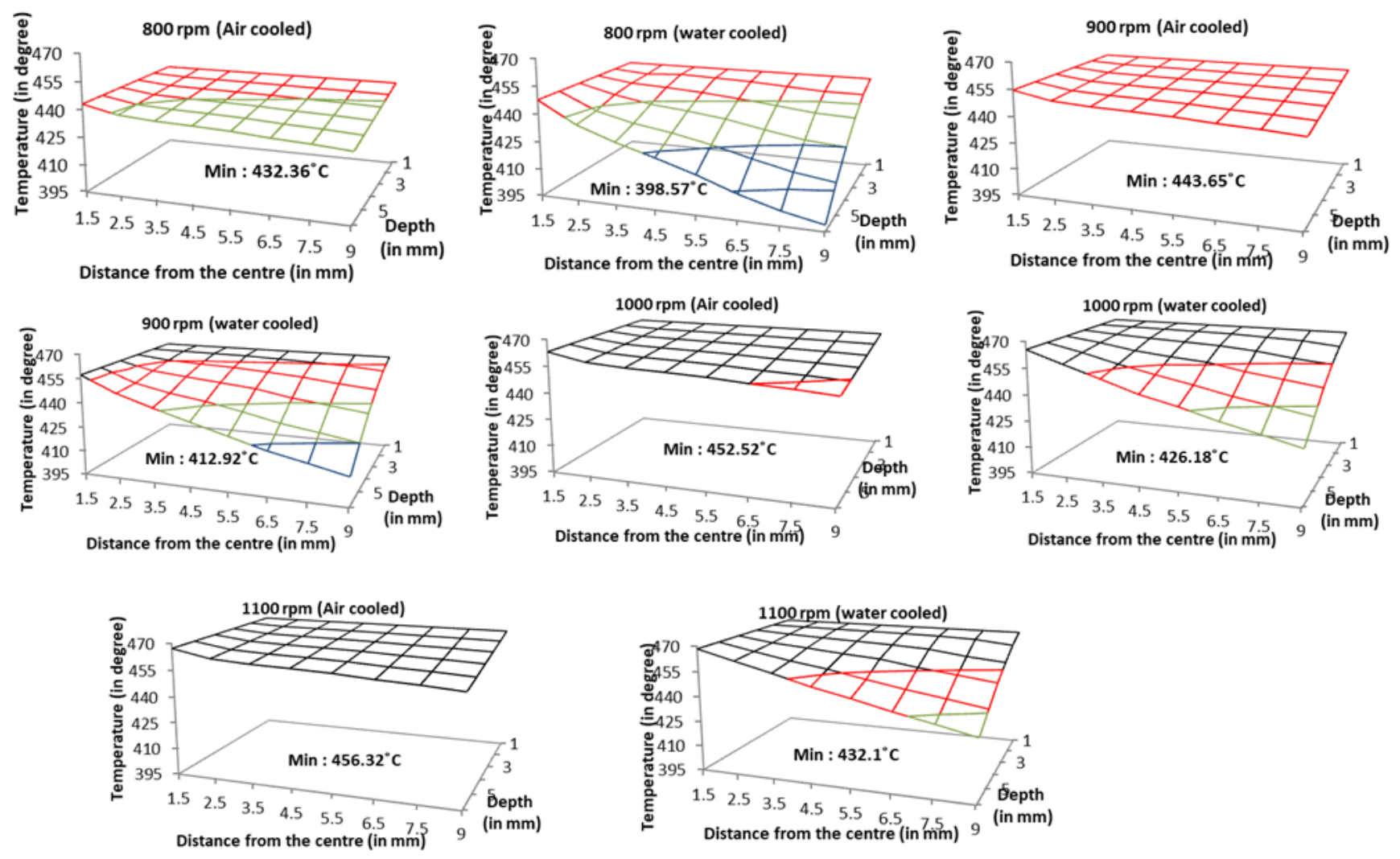

$\square 395-410 \quad \square 410-425 \quad \square$ 425-440 $\square 440-455 \quad \square 455-470$

Fig 5. Temperature distribution in stir zone with respect to the tool rotation speed

\subsubsection{Heat affected zone}

Temperature in the heat affected zone measured by the thermocouples at various points is listed in Table 1. Figure 6 reveals a comparative analysis between numerically estimated temperatures and experimentally obtained temperatures on various trails. Horizontal lines (with negligible inclinations) between experimentally and numerically attained temperatures validate the numerical model whereas the inclined lines indicate the drop in temperature in the heat affected zone with respect to the distance measured from the stir zone.

Increase in tool rotational speed helps to flatten the temperature gradient curve in the stir zone and it also helps to increase the heat affected zone (HAZ) considerably in the joined metal in air cooled friction stir welding. Normally FSW exhibits poor mechanical property in the HAZ due to coarsening of microstructure. It indicates that without increasing the cooling rate, tool rotation cannot be increased beyond a limit. Figure 6 shows considerable reduction in HAZ when heat input reduces through the selection of lower tool rotational speed. But the lesser temperature response in the stir zone increases the material strength under the shoulder and that causes increase in the opposing force for the forward motion of the tool. This increases the wear rate and results in premature failure of the tool pin. And also it develops weld defects due to the insufficient material flow in stir zone. This indicates that the selection of process parameters should be optimised to carry out the joining process in a prescribed range of effective heat input which flattens the temperature gradient curve in stir zone with a tolerable effect in HAZ.

Rate of effective heat supply not only depends on the tool rotation speed but it is also a function of weld speed. To quantify an optimum range of heat supply Pseudo heat index number can be used. It can be estimated by, ${ }^{(22)}$

$$
\text { Pseudo heat index }=\frac{\omega^{2}}{v}
$$

Here, $\omega$ is tool angular velocity and $\mathrm{v}$ is welding speed. Figure 6 shows the variation in temperature field for different heat index numbers. 


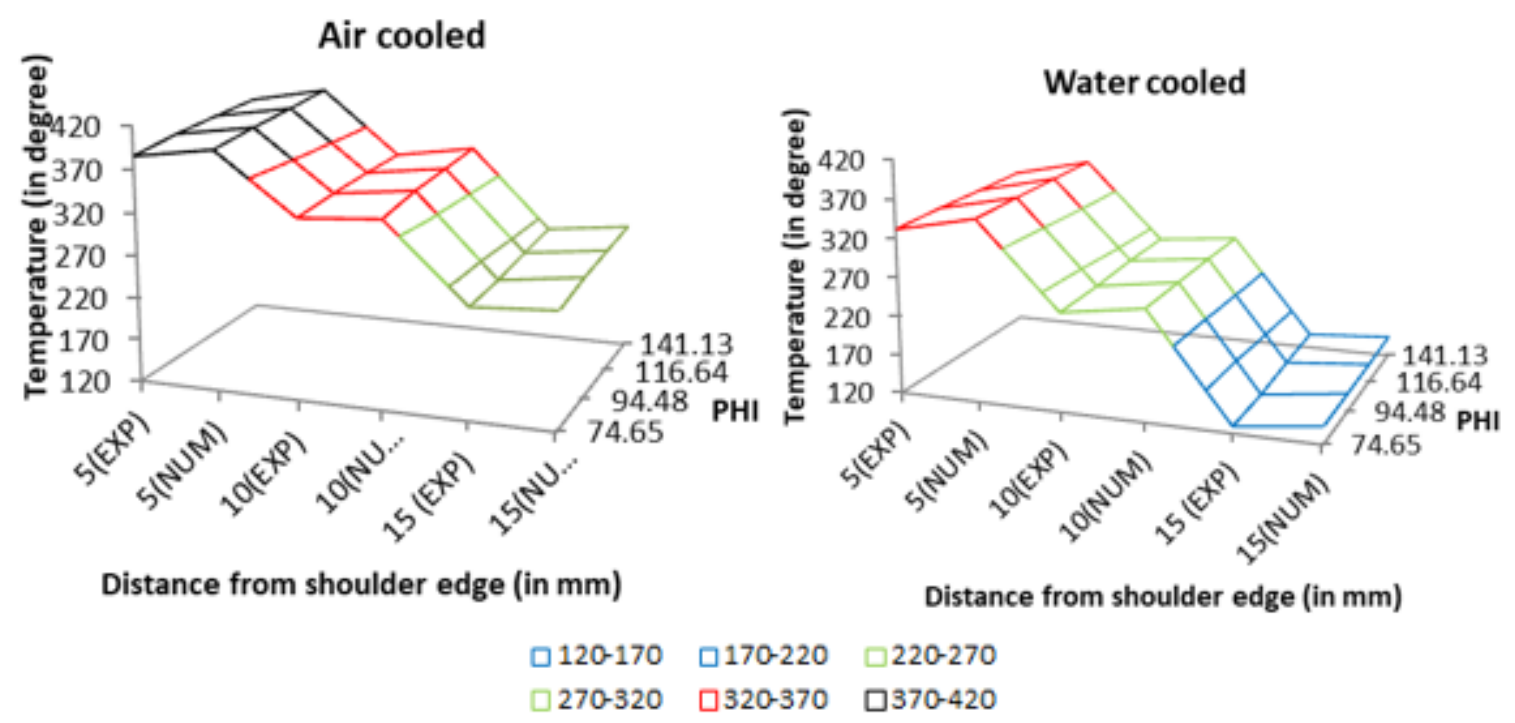

Fig 6. Temperature distribution in heat affected zone

In under water friction stir welding due to the increased heat transfer rate by the surrounding water, very low temperature is observed at all the nodes of heat affected zone compared with air cooled FSW. Reduction in temperature in the heat affected zone reduces the temperature gradient in turn it limits the coarsening of microstructure and improves the strength of the parental metal. Excess cooling rate in water cooled joining process controls the heat affected zone even though the joining process is carried out in higher heat index value. This reveals that unlike air cooled joining process, it is not necessary to evaluate the optimum range of heat index based on the temperature rise in heat affected zone. But the selection of process parameters that delivers lower heat index number leads to insufficient flow rate in stir zone. Optimum range of PHI value in water cooled friction stir welding should be selected in such a way that it increases the process peak temperature as high as possible.

\subsection{Weld quality}

Frictional heat generated along the tool shoulder/matrix interface is the major heat source in friction stir welding. The temperature distribution in every point of the stir zone depends on the heat supply from the top surface which is assisted by the friction heat generated from the pin side/matrix interface. Being an extreme end of stir zone, bottom corner is the point that experiences the lowest temperature rise during the process irrespective of the boundary condition [ Figure 5]. Temperature gradient comparison between the air cooled and water cooled processes clarify that for the same heat input process conditions, water cooled friction stir welding experiences lower temperature at all the points in stir zone. This indicates that heat distribution along the stir zone not only depends on the heat input but also depends on the heat dissipation conditions through its cooling boundaries. So, optimum heat supply should be estimated based on the balance between heating and cooling rates.

Excess heat supply increases the temperature of the top tool contact surface almost equal to the solidus temperature of the parental metal. This temperature rise decreases the shear strength of the material and the top layer in the stir zone tends to become almost a liquid. This leads to excess flash of material spill out from the shoulder edge. These kinds of weld defects are observed in air cooled friction stir welding when the heat index number is greater than 116.64 [ Table 6]. This excess flash reduces the cross-sectional depth of the joint and results in failure in the stir zone whereas in water cooled friction stir welding even though the process is carried out in higher heat index number (141.13), it does not produce excess flash in the edges of the weld joint [ Table 6]. The excess cooling rate by the circulated water reduces the temperature of the material layer closer to the shoulder edge. This tremendous reduction in temperature of this layer seals the material flashes out from the top layer of the stir zone. This is the root cause of defect free weld surface [ Table 6] in water cooled friction stir welding even in excess heat supply. 
Table 6. Weld quality analysis

\begin{tabular}{llllll}
\hline & \multicolumn{2}{c}{ Air cooled process } & \multicolumn{2}{c}{ Water cooled process } \\
PHI & $\begin{array}{l}\text { Microstructure (10X mag- } \\
\text { nification) }\end{array}$ & Weld appearance & PHI & $\begin{array}{l}\text { Microstructure } \\
(10 X \text { magnification) }\end{array}$ & Weld appearance \\
\hline 74.65 & fig(a) & fig(e) & 74.65 & fig(i) & fig(m) \\
94.48 & fig(b) & fig(f) & 94.48 & fig(j) & fig(n) \\
116.64 & fig(c) & fig(g) & 116.64 & fig(k) & fig(o) \\
141.13 & fig(d) & fig(h) & 141.13 & fig(l) & fig(p) \\
\hline
\end{tabular}

\section{Air cooled process}



a

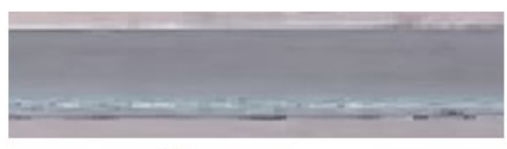

e
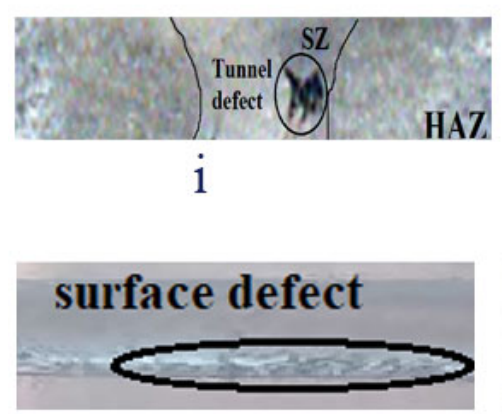

$\mathrm{m}$

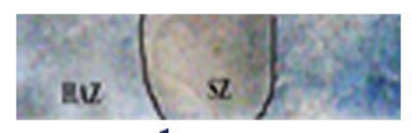

b

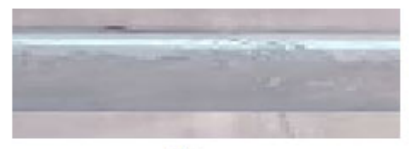

f

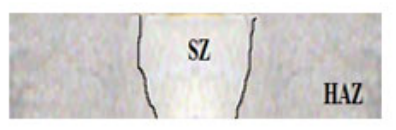

c

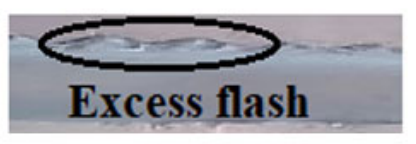

$\mathrm{g}$

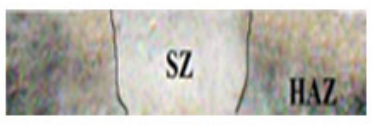

d

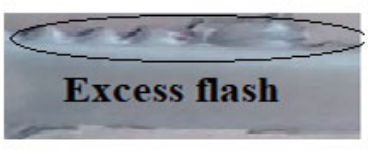

h

\section{Water cooled process}
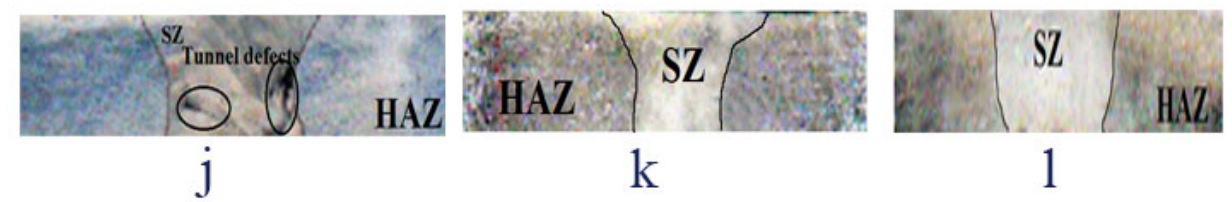

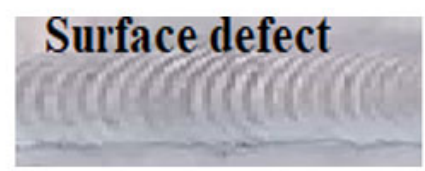

$\mathrm{n}$

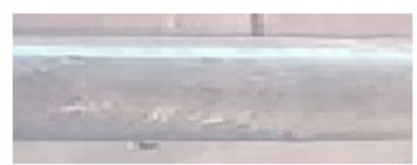

$\mathrm{O}$

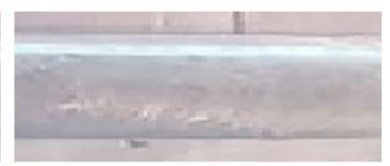

$\mathrm{p}$

On the other hand, insufficient heat supply decreases the temperature towards the bottom corner in the stir zone [ Figure 5]. This decrease in temperature helps the material to retain its shear strength. Especially in water cooled friction stir welding when the heat index number is lesser than 116.64 , forward ploughing of material due to higher weld velocity dominates shear flow around the tool pin. This insufficient material flow causes non-filled stir zone which leads to tunnel defect. These kinds of defects are observed in water cooled friction stir welding which is carried out in lower heat index values 94.47 and 74.64. In air cooled friction stir welding also minor defects are identified at lower heat index value (74.47). This indicates that defect free weld can be obtained only by optimising the tool rotational speed for the selected weld speed in such a way that the process is carried out in optimum heat index value.

\subsection{Micro hardness distribution}

In friction stir welding, effective heat supply and corresponding temperature distribution in stir and heat affected zone create variations in hardness value. Figure 7 compares the variations in hardness values for air cooled and water cooled process. It is noticed that almost all trails exhibit ' $W$ ' shaped curves. ' $W$ ' shape curves resemble that the lowest hardness value falls in heat affected zone for every trail irrespective of its cooling condition. Minimum hardness value is an indicator of low strength region. 
It should be noted that weld defects like excess flash and tunnel defects ( Table 6) makes the stir zone weaker than heat affected zone even though the hardness value is high in this region.
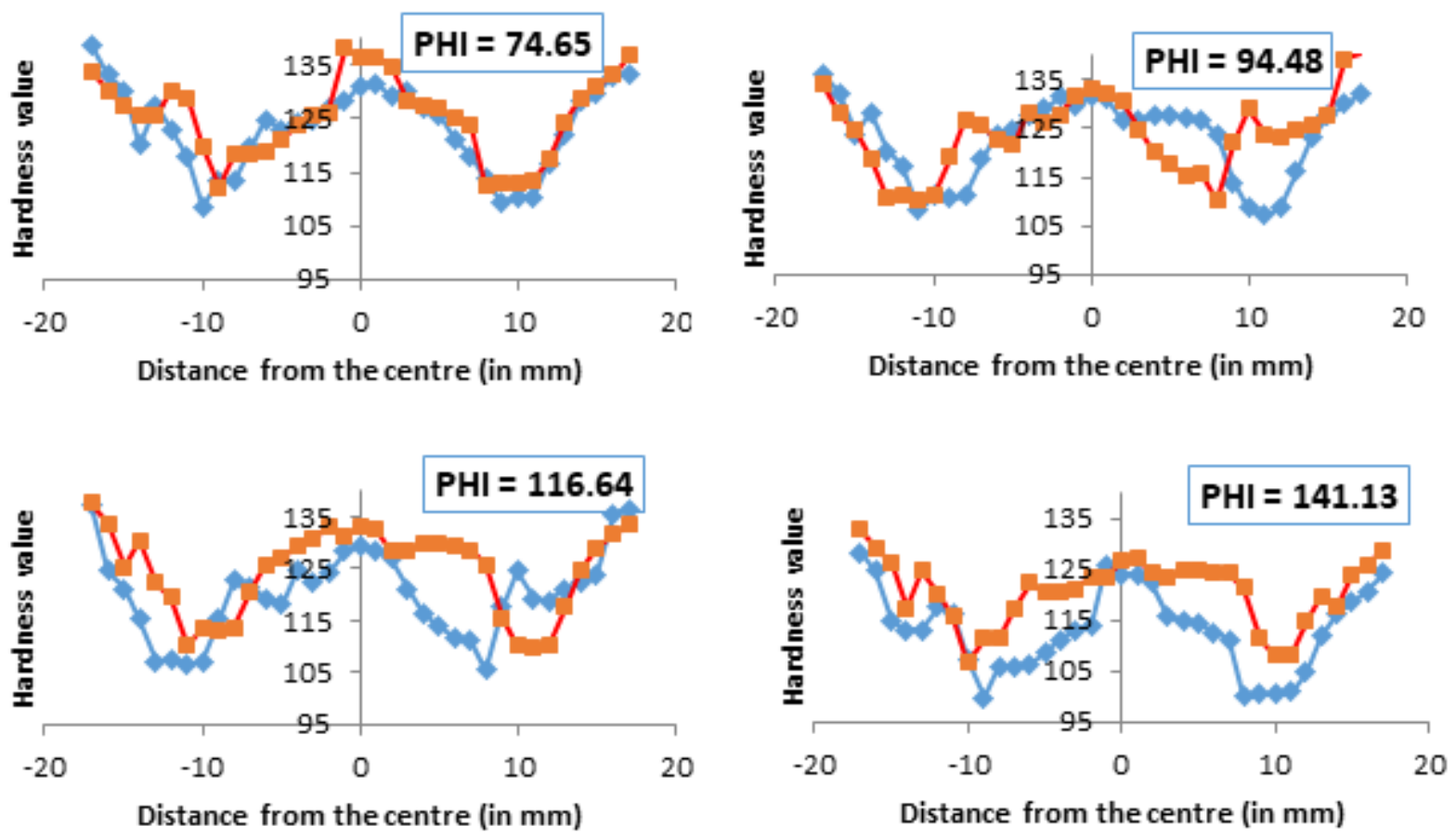

$\longrightarrow$ - air cooled , - water cooled

Fig 7. Micro hardness distribution

Hardness distribution in stir zone is a combined effect of temperature distribution and material flow. Flat faced pin increases the strain rate than cylindrical pin $^{(23)}$ and it results uniform grain size in this zone. There are no considerable fluctuations in hardness values are observed in stir zone ( Figure 7). From this it can be understood that the flat faced pin ensures uniform grain size in stir zone even though the process is carried out with low heat input $(\mathrm{PHI}=74.65)$. It also can be noticed that boundary cooling conditions affects the average hardness value in stir zone. For higher heat input trails, when PHI value greater than 116.64 there is considerable increase in average hardness value for water cooled process. From Figure 5, it can be understood that for the same heat input temperature distribution is lower when the heat dissipation through the boundary is high. This reduction in temperature distribution increases the hardness value in stir zone when the heat transfer through the boundaries is increased by water cooling.

Unlike stir zone, heat affected zone is not affected by material flow. The hardness value distribution in the heat affected zone depends only on temperature distribution. Mode of cooling during the joining process severely affects the temperature in this zone because except heat input boundary, all other boundaries are exposed to heat dissipating medium. Figure 7 shows there is huge difference in minimum hardness value between air cooled and water cooled process for same PHI number. It can also be noticed that lowest hardness value of 99.93 is recorded in air cooled process carried out with higher heat input $(\mathrm{PHI}=141.13)$. Minimum hardness value observed in water cooled joint is always higher than the joint obtained through air cooled process. This indicates that the higher cooling rate improves the weld quality.

\subsection{Tensile properties}

Tensile strength of the weld joint depends on the minimum hardness value and weld defect. Specimens are cut using wire EDM form the obtained friction stir welded plates. Specimens for the tensile test are prepared as per ASTM E8. From Table 7, it can be concluded that excess heat supply reduces the weld strength in air cooled friction stir welding. When the PHI is more than 94.47 the temperature rise in stir zone also increases the temperature in heat affected zone. Maximum temperature of $395.67^{\circ} \mathrm{C}$ 
is observed in heat affected zone when the PHI number is 141.13 in air cooled process ( Table 1). The increase in temperature increases the grain size of the material in heat affected zone. This coarsening of grain size decreases the density of strengthening agents in the alloy that result in lower strength regions. For the air cooled process it can be noted that when the PHI increases joint strength decreases. It is also observed that when PHI is reduced to 74.64, although the hardness value is comparatively higher, its joint strength is lower. As the weaker zone is observed in stir zone ( Table 7), it can be concluded that this is due to the weld defect in stir zone caused by the insufficient heat input.

Table 7. Summary of joint quality and strength analysis

\begin{tabular}{|c|c|c|c|c|c|c|c|}
\hline $\begin{array}{l}\text { Mode of } \\
\text { cooling }\end{array}$ & $\begin{array}{l}\text { Pseudo heat } \\
\text { index }\end{array}$ & $\begin{array}{l}\text { lowest } \\
\text { hardness }\end{array}$ & $\begin{array}{l}\text { Yield strength } \\
(\mathrm{MPa})\end{array}$ & $\begin{array}{l}\text { Ultimate } \\
\text { strength }(\mathrm{MPa})\end{array}$ & $\begin{array}{l}\text { Weaker } \\
\text { zone }\end{array}$ & Weld quality & Heat input \\
\hline \multirow{4}{*}{ Air cooled } & 74.6496 & 108.64 & 284.23 & 344.23 & $\mathrm{SZ}$ & Minor defects & Insufficient heat \\
\hline & 94.4784 & 107.14 & 291.45 & 361.43 & HAZ & Defect free & Optimum heat \\
\hline & 116.64 & 105.59 & 279.72 & 342.67 & HAZ & Excess flash & Excess heat \\
\hline & 141.134 & 99.93 & 269.32 & 335.14 & HAZ & Excess flash & Excess heat \\
\hline \multirow{4}{*}{$\begin{array}{l}\text { Water } \\
\text { cooled }\end{array}$} & 74.6496 & 105.26 & 275.23 & 338.12 & SZ & Tunnel defect & Insufficient heat \\
\hline & 94.4784 & 109.09 & 286.25 & 347.89 & $\mathrm{SZ}$ & Tunnel defect & Insufficient heat \\
\hline & 116.64 & 110.64 & 303.78 & 371.54 & HAZ & Defect free & Optimum heat \\
\hline & 141.134 & 113.64 & 309.65 & 373.89 & HAZ & Defect free & Optimum heat \\
\hline
\end{tabular}

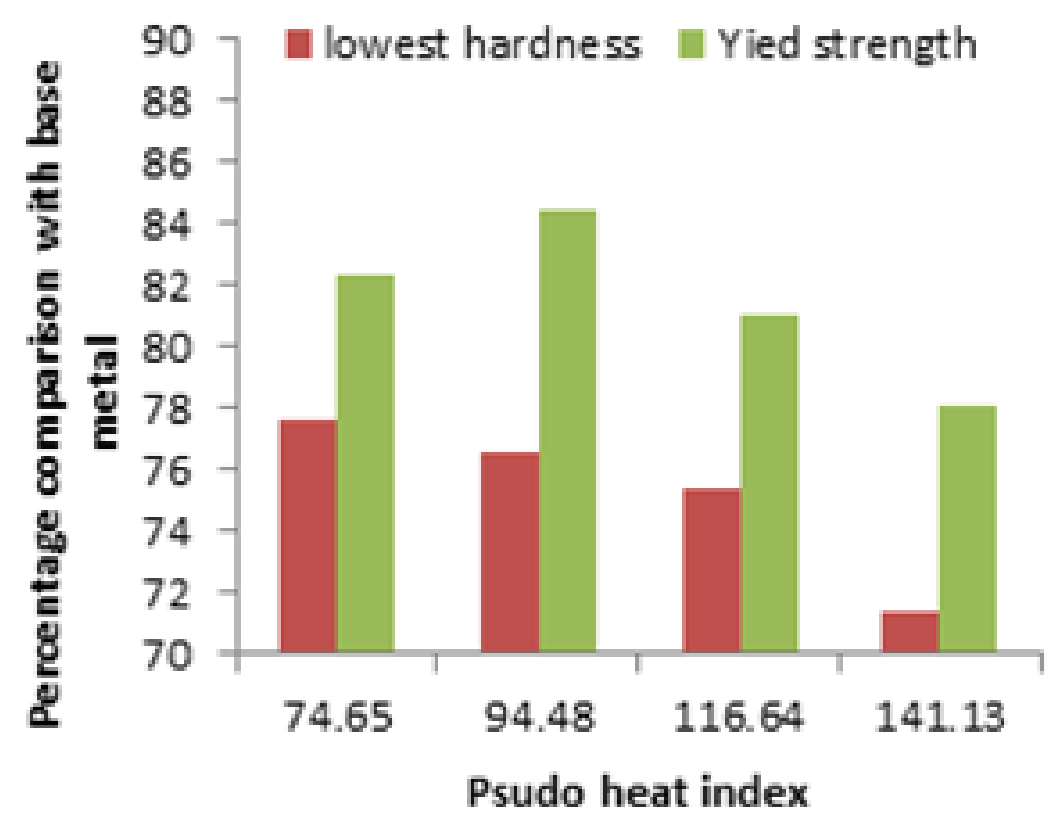

Fig 8. Air cooled friction stir welding 


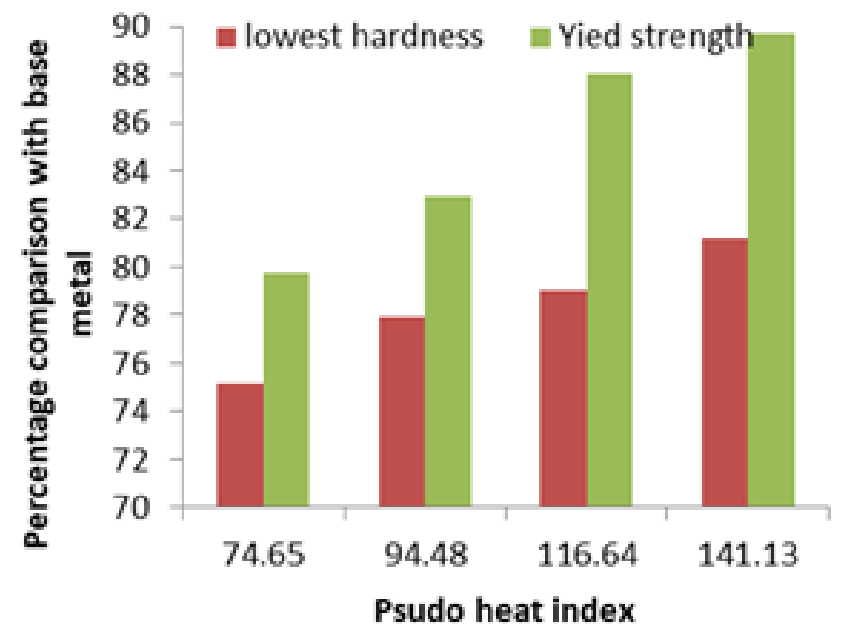

Fig 9. water cooled friction stir welding

Enhanced heat dissipation in water cooled friction stir welding reduces the temperature tremendously even when the process is carried out in excess heat supply. For PHI number 141.13, maximum temperature rise is $336.34^{\circ} \mathrm{C}$ when the boundaries are cooled by water. This temperature is $59.33^{\circ} \mathrm{C}$ lower than the temperature observed in air cooled process for the same PHI number. From this it is understood that even at excess heat supply underwater welding exhibits superior weld quality. A maximum of $89.75 \%$ of joint efficiency is achieved in water cooled friction stir welding when the PHI number is 141.13 . On the other hand, in lower PHI number (74.64), the lowest joint strength of $75.18 \%$ is obtained ( Figure 8) due to the tunnel defect resulted by insufficient heat supply. In Comparison to air cooled process the drastic change in joint efficiency ( Figure 9 ) of water cooled process indicates that its temperature response to the heat supply is comparatively high.

\subsection{Optimum process condition}

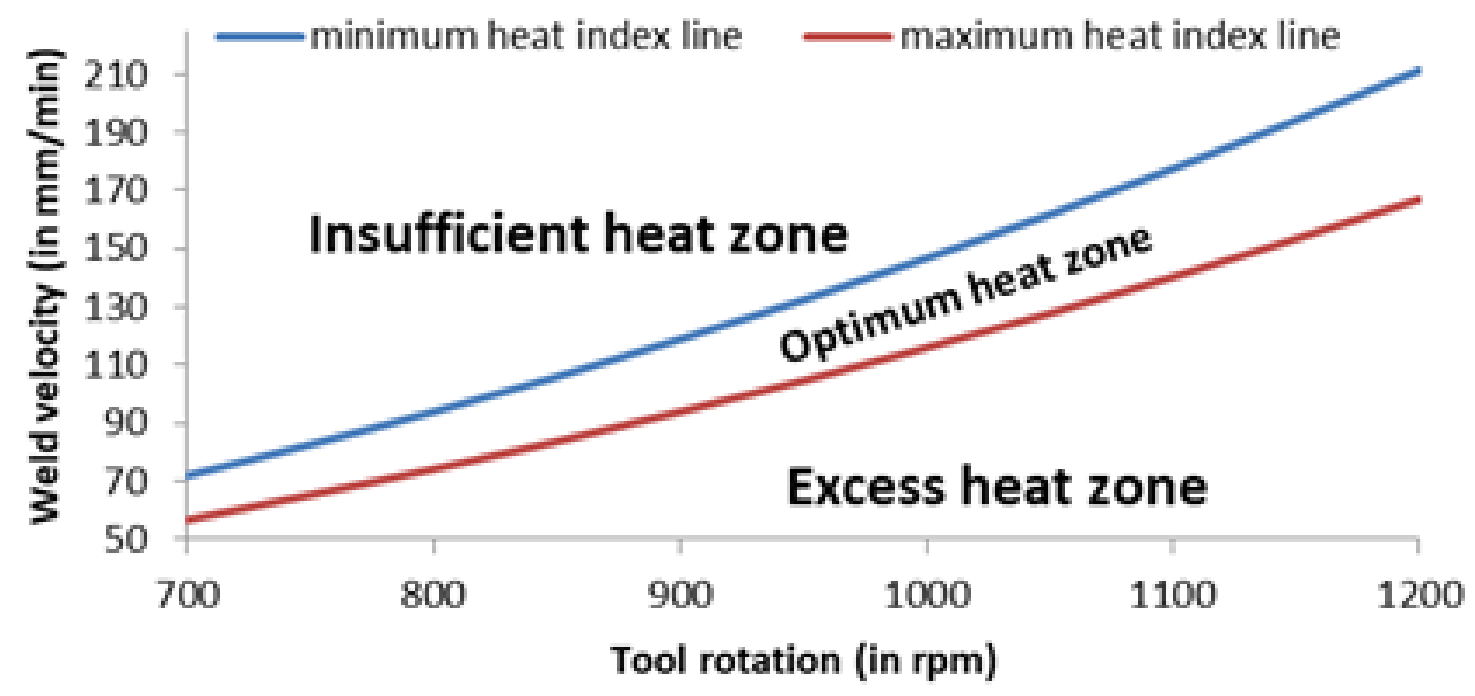

Fig 10. Optimum process window (Air cooled) 


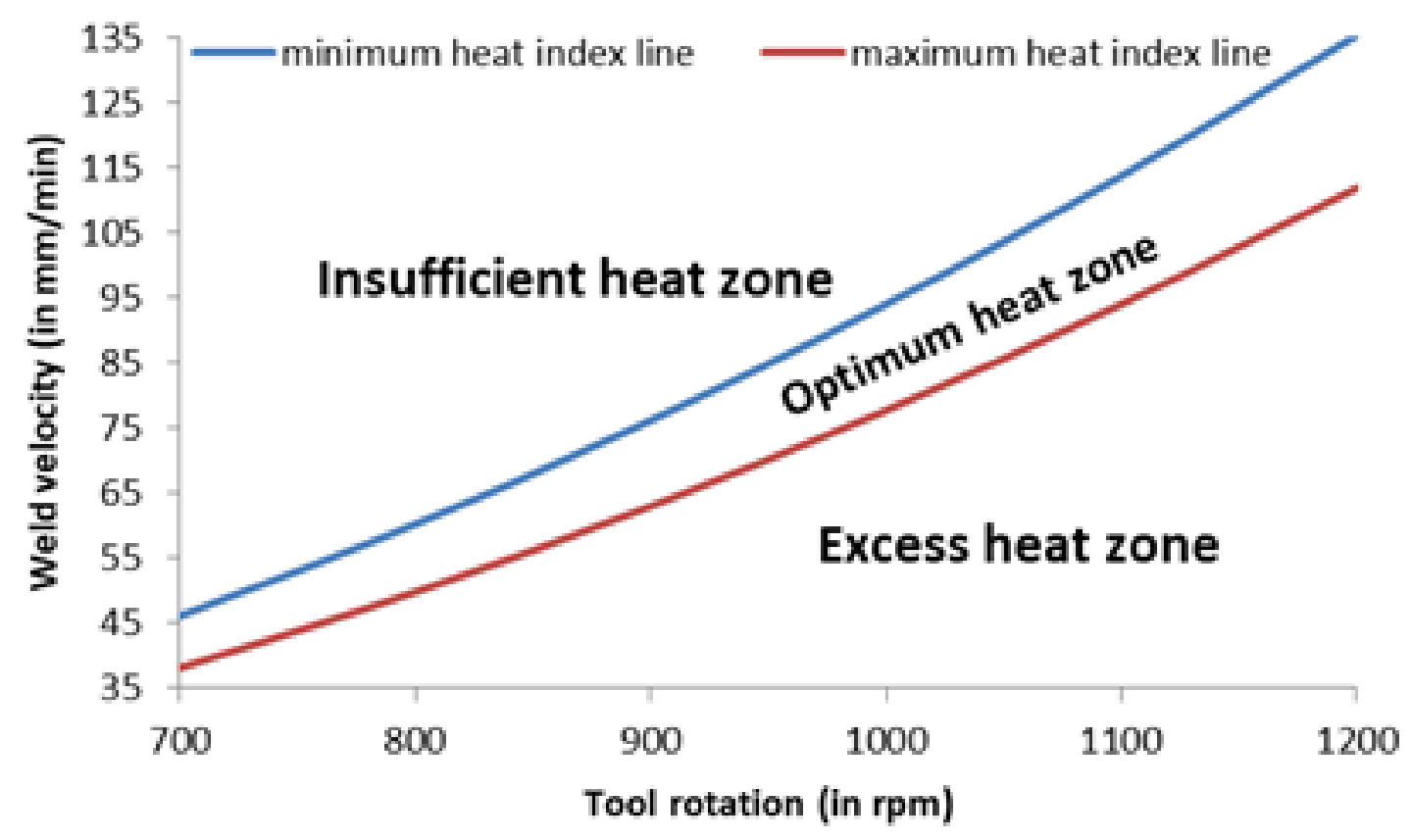

Fig 11. Optimum process window (Water cooled)

Defect free weld depends on the material flow in the stir zone. Uniform temperature distribution in the stir zone ensures sufficient material flow. This indicates that optimum process conditions can be explained based on the highest and lowest temperatures observed in the stir zone. Paul et al. ${ }^{(23)}$ related the material flow strength with temperature rise and concluded that the material reaches its empirical softening regime at a temperature of $450^{\circ} \mathrm{C}$. From the present study it is observed that better weld quality is achieved in air cooled process when chosen PHI is 94.48 ( Figure 8) at which maximum temperature in stir zone is $454.65^{\circ} \mathrm{C}$. Steep reduction in tool torque beyond this PHI value reveals that material loses its strength drastically when the process temperature is more than $454.65^{\circ} \mathrm{C}$. When the PHI value reaches 116.64, material layer nearer to the tool contact surface reaches a maximum temperature of $463.52^{\circ} \mathrm{C}$ which is much higher than the material softening temperature ( Figure 5). In this temperature material loses its strength completely and almost becomes a liquid. This low strength material layer spills out through the shoulder edge as it could not withstand the tool vertical force that causes excess flash. It indicates that the process temperature cannot be increased more than $463.52^{\circ} \mathrm{C}$. From all these factors it can be understood that optimum PHI range for air cooled friction stir welding is from 94.48 to 116.64 .

For water cooled process, weld defects are observed even the process peak temperature is $457^{\circ} \mathrm{C}$ because at this temperature the minimum temperature observed in stir zone is $412.92^{\circ} \mathrm{C}$ which is much lower than the softening temperature ( Figure 5). Defect free weld is achieved only at excess heat supply when the PHI is more than 116.64. This indicates that the process should be carried out with excess heat supply to meet out excess heat dissipation through the water cooled boundaries. As there is no weld defect like excess flash observed in excess heat supply the optimum process conditions can be fixed based on PHI more than 116.64. It is also understood that when the increase in PHI value is more than 141.13, it does not impact much on the temperature rise in the stir zone as the material in the tool/matrix contact surface loses its strength completely and the frictional heat generation meets its saturation point. This indicates that the maximum range of optimum process condition can be fixed based on the PHI value of 141.13. The optimal range of process parameters to be selected to attain the optimum process input conditions are shown in Figures 10 and 11.

\section{Conclusion}

Effect of air and water cooling on temperature distribution during the process in stir and heat affected zone is estimated through an integrated experimental and numerical analysis. Comparing the obtained temperature distribution with empirical material softening temperature, the present study outlines a novel approach to develop an optimum process parameter selection chart. 
Considering Pseudo heat index (PHI) as a combined effect tool rotation speed and welding speed, following results are obtained from the friction stir welding on AA2024-T3 metal pates:

- PHI for a process should be selected in such a way that it rises the temperature in stir zone more than the material softening temperature $\left(450^{\circ} \mathrm{C}\right.$ for $\left.\mathrm{AA} 2024-\mathrm{T} 3\right)$.

- Rise of temperature more than the material softening temperature in stir zone reduces material strength that ensures minimum opposing force for the tool movement and defect free weld.

- Optimum PHI ranges from 94.48 to 116.64 for air cooled friction stir welding. Further, increase in heat input eradicates the joint strength whereas for water cooled process, defect free weld is achieved only at excess heat supply when the PHI is more than 116.64 .

- Although the weld quality is directly proportional to the increase in process peak temperature in water cooled process, when the process temperature is increased more than $465.58^{\circ} \mathrm{C}$, tool/matrix contact surface loses its strength completely and leads the frictional heat generation to meet its saturation point.

\section{References}

1) Bayazid SM, Farhangi H, Ghahramani A. Effect of Pin Profile on Defects of Friction Stir Welded 7075 Aluminum Alloy. Procedia Materials Science. 2015;11:12-16. Available from: https://dx.doi.org/10.1016/j.mspro.2015.11.013.

2) Ilangovan M, Boopathy SR, Balasubramanian V. Effect of tool pin profile on microstructure and tensile properties of friction stir welded dissimilar AA 6061-AA 5086 aluminium alloy joints. Defence Technology. 2015;11(2):174-184. Available from: https://dx.doi.org/10.1016/j.dt.2015.01.004.

3) Leon JS, Jayakumar V. Effect of Tool Shoulder and Pin Cone Angles in Friction Stir Welding using Non-circular Tool Pin. Journal of applied and computational mechanics. 2020;6(3). Available from: https://doi.org/10.22055/JACM.2019.29340.1585.

4) Sabeerushen JR, Kumar V. Influence of tool pin profile on the tensile behavior of dissimilar friction stir welded joints of aluminium alloys. International Journal of Innovative Research in Science, Engineering and Technology. 2016;5:5376-5382. Available from: https://doi.org/10.15680/IJIRSET.2016.0504168.

5) Gharaibeh N, Jawdat A, Al-Jarrah S, Sawalha. Effect of pin profile mechanical properties of $6061 \mathrm{Al}$ alloy welded joints prepared by friction stir welding. International Journal of mechanics and applications. 2016;6(3):39-42. Available from: https://doi.org/10.5923/j.mechanics.20160603.01.

6) Leon JS, Jayakumar V. Transient heat input model for friction stir welding using non-circular tool pin. FME Transactions. 2020;48(2):137-142. Available from: https://dx.doi.org/10.5937/fmet2001137l.

7) peng Liang X, zhong Li H, Li Z, Hong T, Ma B, dan Liu S, et al. Study on the microstructure in a friction stir welded 2519 -T87 Al alloy. Materials \& Design. 2012;35:603-608. Available from: https://dx.doi.org/10.1016/j.matdes.2011.10.009.

8) Sheng X, Li K, Wu W, Yang Y, Liu Y, Zhao Y, et al. Microstructure and Mechanical Properties of Friction Stir Welded Joint of an Aluminum Alloy Sheet 6005A-T4. Metals. 2019;9(11):1152-1152. Available from: https://dx.doi.org/10.3390/met9111152.

9) Leon JS, Jayakumar. An investigation of analytical modeling of friction stir welding. International Journal of Mechanical and Production Engineering Research and Development. 2019;9(1):179-190. Available from: https://doi.org/10.24247/ijmperdfeb201918.

10) Sivaraj P, Kanagarajan D, Balasubramanian V. Effect of post weld heat treatment on tensile properties and microstructure characteristics of friction stir welded armour grade AA7075-T651 aluminium alloy. Defence Technology. 2014;10(1):1-8. Available from: https://dx.doi.org/10.1016/j.dt.2014.01.004. doi:10.1016/j.dt.2014.01.004.

11) Fratini L, Buffa G, Shivpuri R. Mechanical and metallurgical effects of in process cooling during friction stir welding of AA7075-T6 butt joints. Acta Materialia. 2010;58(6):2056-2067. Available from: https://dx.doi.org/10.1016/j.actamat.2009.11.048.

12) Liu HJ, Zhang HJ, Yu L. Effect of welding speed on microstructures and mechanical properties of underwater friction stir welded 2219 aluminum alloy. Material Design. 2011;32:1548-1553.

13) Li M, Zhang C, Wang D, Zhou L, Wellmann D, Tian Y. Friction Stir Spot Welding of Aluminum and Copper: A Review. Materials. 2019;13(1):156-156. Available from: https://dx.doi.org/10.3390/ma13010156.

14) Soundararajan V, Zekovic S, Kovacevic R. Thermo-mechanical model with adaptive boundary conditions for friction stir welding of Al 6061. International Journal of Machine Tools and Manufacture. 2005;45(14):1577-1587. Available from: https://dx.doi.org/10.1016/j.ijmachtools.2005.02.008.

15) Mehta M, Reddy GM, Rao AV, De A. Numerical modeling of friction stir welding using the tools with polygonal pins. Defence Technology. 2015;11(3):229236. Available from: https://dx.doi.org/10.1016/j.dt.2015.05.001.

16) Garg A, Raturi M, Bhattacharya A. Influence of additional heating in friction stir welding of dissimilar aluminum alloys with different tool pin profiles. The International Journal of Advanced Manufacturing Technology. 2019;105(1-4):155-175. Available from: https://dx.doi.org/10.1007/s00170-019-04186-z.

17) Arora A, De A, DebRoy T. Toward optimum friction stir welding tool shoulder diameter. Scripta Materialia. 2011;64(1):9-12. Available from: https://dx.doi.org/10.1016/j.scriptamat.2010.08.052.

18) J SL, G B, V J. Analytical and experimental investigations of optimum thermomechanical conditions to use tools with non-circular pin in friction stir welding. The International Journal of Advanced Manufacturing Technology. 2020;107(11-12):4925-4937. Available from: https://dx.doi.org/10.1007/ s00170-020-05341-7.

19) Cui S, Chen ZW, Robson JD. A model relating tool torque and its associated power and specific energy to rotation and forward speeds during friction stir welding/processing. International Journal of Machine Tools and Manufacture. 2010;50:1023-1030. Available from: https://dx.doi.org/10.1016/j. ijmachtools.2010.09.005.

20) Hamilton C, Dymek S, Sommers A. A thermal model of friction stir welding in aluminum alloys. International Journal of Machine Tools and Manufacture. 2008;48(10):1120-1130. Available from: https://dx.doi.org/10.1016/j.ijmachtools.2008.02.001.

21) Zhang ZH, Li WY, Shen J. Effect of back plate diffusivity on microstructure and mechanical properties of friction stir welded joints. Materials and Design. 2013;50:551-557.

22) Hamilton C, Kopyściański M, Senkov O, Dymek S. A Coupled Thermal/Material Flow Model of Friction Stir Welding Applied to Sc-Modified Aluminum Alloys. Metallurgical and Materials Transactions A. 2013;44(4):1730-1740. Available from: https://dx.doi.org/10.1007/s11661-012-1512-y. 
23) Colegrove PA, Shercliff HR, Zettler R. Model for predicting heat generation and temperature in friction stir welding from the material properties. Science and Technology of Welding and Joining. 2007;12:284-297. Available from: https://dx.doi.org/10.1179/174329307x197539. 